\title{
Ullmann Reaction Optimization within Bitolyl and Decafluorobiphenyl Synthesis
}

\author{
A. V. KOLOTAEV, A. L. RAZINOV and D. S. KHACHATRYAN* \\ The Federal State Unitary Enterprise «Institute of Chemical Reagents and High Purity Chemical \\ Substances of National Research Centre «Kurchatov Institute», Bogorodsky val str.3, Moscow, Russia. \\ ${ }^{*}$ Corresponding author E-mail: derenik-s@yandex.ru \\ http://dx.doi.org/10.13005/ojc/340249
}

(Received: September 29, 2017; Accepted: January 20, 2018)

\section{ABSTRACT}

This article describes the investigation of the cross-coupling Ullman's reaction of aryl halides under various conditions to find optimal scalable method of biaryl synthesis and the development of preparative methods of synthesizing 3,3'-bitolyl and perfluorobipfenyl, which are valuable semi-products of organic synthesis.

Keywords: Ullmann reaction, Bitolyl, Decafluorobiphenyl, Polymer materials, Polyarenes, Polyimides.

\section{INTRODUCTION}

Previously the authors investigated the aryl halides cross-coupling reaction to produce polyarenes, particularly quaterphenyl derivatives, within the framework of the FTP «Development of methods of producing quaterphenyl derivatives» (Agreement \# 16.168.25.2002). Quaterphenyl derivatives are a substances with a high scintillation ${ }^{1-2}$ activity and therefore is promising for use in the detection of low-level radiators for medical research, geological prospecting and environmental monitoring. During the study the authors thoroughly investigated 3-halotoluene dimerization reaction to produce 3,3'-bitolyl, an intermediate compound within polyarene synthesis.

The process of developing 3,3'-bitolyl was based on reported methods split into three groups: - Ullmann reaction and its variations

- $\quad$ Cross-coupling reactions with active metals over catalysts

Cross-coupling reactions between magnesium-organic compounds and 3-halotoluenes over catalysts 
As Table 1 shows, given the above-mentioned criteria, the most suitable test methods are those using the combination of active metals and 3-bromotoluene or 3-iodotoluene. The drawback of the first three methods is using relatively expensive catalysts, while that of the fourth method is using a fire-hazardous reagent.

Table 1: Reported conditions of 3-iodotoluene from literature

Reaction conditions

Output, \%

Potassium phosphate, 4,4,5,5-tetramethyl-1,3,2- dioxaborolane-2-yl-4,4,5,5$95^{3}$ tetramethyl-1,3,2-dioxaborolane, palladium-iron complex in dimethylformamide Palladium acetate, potassium carbonate in butanone

18-crown-6, zinc, $\mathrm{Pd} / \mathrm{C}$ in water

$76^{4}$

Sodium in diethyl ether

$61^{5-6}$

$-7-8$

Copper

$35^{9-10}$

Copper in dimethylformamide

\section{MATERIALS AND METHODS}

A series of experiments was conducted to determine the optimal conditions for performing 3.3'-bitolyl and decafluorodiphenyl production reactions. The structure and purity of the products produced were confirmed by NMR and GC methods.

3-Iodotoluene, 3-bromotoluene, perfluorobromobenzene and other chemicals were equipped from Aldrich, Acros and Sigma chemical companies and used without further purification. All chemicals and solvents used in the preparation and characterization were of analytical grade. ${ }^{19} \mathrm{~F}-\mathrm{NMR}$ spectra were obtained with a model Bruker $\mathrm{AM}(283 \mathrm{MHz})$ spectrometer for using $\mathrm{CDCl}_{3}$ solution in an appropriate deuterated solvent.The chemical shift are reported in ppm using tetramethylsilane (TMS) as the internal reference. Quantitative sample analysis was carried out using gas chromatography (GC), which, in turn, was performed using gas chromatograph "Chromatec Crystal 5000.2», equipped with flame ionization detector and $30-\mathrm{m}$ long fused silica column BP-1 (inner diameter $0.32 \mathrm{~mm}$ ).

\section{EXPERIMENTAL}

\section{Activated copper production Variation 1}

$8.1 \mathrm{~g}$ copper is mixed in the solution comprising $1.3 \mathrm{~g}$ iodine and $80-\mathrm{ml}$ acetone, followed by flushing with concentrated hydrochloric acid in acetone $(20 \mathrm{ml}$ of $\mathrm{HCl}(36 \%)$ per $20 \mathrm{ml}$ of acetone) and $1 \mathrm{~h}$ drying in the vacuum oven.

\section{Variation 2}

Cold saturated $\mathrm{CuSO}_{4}$ solution is poured into porcelain cup, followed by portion-wise adding zinc powder (it must contain no impurities non-soluble in $10 \% \mathrm{HCl}$ ) sifted through fine mesh. After 10-g zinc powder has been added, the solution is heated to $80^{\circ} \mathrm{C}$, with further zinc portions being added into hot solution. Adding $\mathrm{Zn}$ is stopped when the solution heated to $80^{\circ} \mathrm{C}$ is still thin blue (fractured copper powder per $100 \mathrm{ml}$ falls to the bottom as heavy dark red deposit).

Supernatant liquid is drained, while the deposit is probably thoroughly flushed with water by means of decantation. Then, to remove zinc traces, $10 \% \mathrm{HCl}$ is added to the deposit, accompanied by simultaneous mixing, till the solution stops boiling. The deposits is flushed by means of decantation again, sucked in the Buchner funnel and flushed in the funnel, till flushing water shows neutral reaction, followed by flushing with ethyl alcohol and diethyl ether. The copper produced is vacuum-dried.

\section{Bis-3,3'-bitolyl production using copper}

Method A. $10 \mathrm{~g}$ 3-iodotoluene and $20 \mathrm{~g}$ activated copper powder are mixed in a heat-resistant test tube. The mixture produced is heated to $270{ }^{\circ} \mathrm{C}$, followed by $30 \mathrm{~min}$. dwelling at 
this temperature. The reaction mass is treated with boiling heptane thrice. The solution was then decanted and vacuum-stripped, with the residue being vacuum-distilled to collect the fraction of $155-180{ }^{\circ} \mathrm{C} / 15-20 \mathrm{~mm} \mathrm{Hg}$.

Method B. $10 \mathrm{~g}$ 3-iodotoluene and $50 \mathrm{ml}$ dimethylformamide are fed into 100-ml three-head flask equipped with reflux condenser, temperature gauge and magnetic mixer. The solution is heated to the boiling point, followed by adding a single portion $(10 \mathrm{~g})$ of copper powder.

The reaction mass is boiled for $40 \mathrm{~h}$, followed by adding another $10 \mathrm{~g}$ copper powder and another $40 \mathrm{~h}$ boiling. The reaction mass is then cooled down, poured into 200-ml water and filtered out. The deposit is flushed thrice, using $50 \mathrm{ml}$ heptane each time. Water and organic layers are separated. Heptane is stripped, while the deposit is vacuum-distilled through water-jet pump to collect the fraction of $155-180{ }^{\circ} \mathrm{C} / 15-20 \mathrm{~mm} \mathrm{Hg}$ (lit ${ }^{12} 153-155^{\circ} \mathrm{C} / 18 \mathrm{~mm} \mathrm{Hg}$ ).

\section{Decafluorobiphenyl production using copper} $8.0 \mathrm{~g}$ (34.9 mmol) perfluorobromobenzene is dissolved in dry DMF (15 ml), followed by adding $8.6 \mathrm{~g}$ (135.2 mmol) activated copper, 5-hour mixing under argon atmosphere at the boiling point ( ${ }^{19} \mathrm{~F}$ NMR $-100 \%$ conversion) and cooling down to room temperature. The deposit is filtered out and flushed with DMF $(15 \mathrm{ml})$. Joint organic fractions are diluted with excessive water $(300 \mathrm{ml})$, while the deposit is filtered out, air-dried and distilled to collect the fraction with the boiling point of $94-95^{\circ} \mathrm{C} / 20 \mathrm{~mm} \mathrm{Hg}$, accompanied by simultaneous cooling down of the receiver with ice. The output is $5.4 \mathrm{~g} \mathrm{(92 \%} \mathrm{of}$ estimated value) of white solid substance with the boiling point of $68.5-69.5{ }^{\circ} \mathrm{C}$. The purity per $\mathrm{GC}$ is $99.9 \%$

${ }^{19} \mathrm{~F}$ NMR $\left(283 \mathrm{MHz}, \mathrm{CDCl}_{3}\right) \delta-137.37$ (ddd, $\mathrm{J}=19.1,9.2,5.3 \mathrm{~Hz}$ ), -149.50 - -150.06 (multiplet), -160.25 (tdd, $\mathrm{J}=22.2,11.1,5.9 \mathrm{~Hz}$ ).

\section{Decafluorobiphenyl production using zinc}

$32.7 \mathrm{~g}(0.500 \mathrm{~mol})$ zinc powder suspension and $1.00 \mathrm{~g}$ (0.006 mol) copper (II) acetate are simultaneously mixed in $120 \mathrm{ml}$ absolute DMF and heated to $140{ }^{\circ} \mathrm{C}$ for $40 \mathrm{~min}$, followed by cooling down to $100{ }^{\circ} \mathrm{C}$ and adding $247 \mathrm{~g}$ (1.000 mol) bromopentafluorobenzene drop-wise at 2-2.5 $\mathrm{ml} / \mathrm{min}$. speed, so the reacting mass would be slowly heated to its boiling point. After adding bromopentafluorobenzene is over, the reacting mixture is boiled for $6 \mathrm{~h}$, cooled down to $60-70{ }^{\circ} \mathrm{C}$ and poured into cold water, followed by adding 23-32 ml of concentrated hydrochloric acid. Once two layers have formed, the upper one is decanted, while the lower one is treated with concentrated hydrochloric acid $(2 \times 30 \mathrm{ml})$ and concentrated $\mathrm{HNO}_{3}(3 \times 15 \mathrm{ml})$, followed by adding hot water $\left(60-70^{\circ} \mathrm{C}\right)$. The oil produced is separated and dwelled for several $h$ in the refrigerator. The solid product is filtered out from unreacted bromopentafluorobenzene and recrystallized from hexane, followed by producing $117 \mathrm{~g}$ of decafluorobiphenyl, with its purity of $97-98 \%$ ( $\mathrm{GC}$ data) and $\mathrm{T}_{\text {boiling }}=68-69^{\circ} \mathrm{C}$. The output is $70 \%$.

${ }^{19} \mathrm{~F} \mathrm{NMR}\left(283 \mathrm{MHz}, \mathrm{CDCl}_{3}\right) \delta-137.37$ (ddd, $\mathrm{J}=19.1,9.2,5.3 \mathrm{~Hz}),-149.50--150.06(\mathrm{~m}),-160.25$ (tdd, J = 22.2, 11.1, $5.9 \mathrm{~Hz}$ ).

\section{Grignard reagent production from 3-bromotoluene} 3-Bromotoluene $(171.0 \mathrm{~g}, 1.000 \mathrm{~mol})$ is dissolved in $250 \mathrm{ml}$ THF. The reaction is initiated by adding 2-4 $\mathrm{ml}$ of ethylbromide per $1 \mathrm{~mol}$ of magnesium $(24.3 \mathrm{~g})$ and $15-20 \mathrm{ml}$ of aryl halide's THF solution, accompanied by simultaneous mixing. As the reaction starts, the remaining solution is swiftly added drop-wise to ensure selfmaintaining boiling. After adding aryl halide's THF solution is over, the reaction mixture is mixed at the boiling point for $2.5 \mathrm{~h}$, till magnesium is completely dissolved.

\section{Bitolyl production from magnesium-organic derivative, using nickel acetylacetonate}

A catalyst, nickel acetylacetonate $(1.2 \mathrm{~g}, 0.0047 \mathrm{~mol})$, is added to bromotoluene $(40.0 \mathrm{~g}, 0.234 \mathrm{~mol})$ solution in tetrahydrofuran $(150 \mathrm{ml})$ under nitrogen atmosphere. Grignard reagent solution, produced from 3-bromotoluene $(40.0 \mathrm{~g}, 0.234 \mathrm{~mol})$ and magnesium $(5.9 \mathrm{~g}, 0.245$ $\mathrm{mol})$, in tetrahydrofuran $(80 \mathrm{ml})$ is added drop-wise to the initial mixture at the speed that maintain gentle boiling. The reaction mixture is boiled for three hours, followed by THF stripping and treating the deposit produced with $200 \mathrm{ml}$ water and $300 \mathrm{ml}$ 
hexane. To completely dissolve the residue a hydrochloric is added, followed by hexane extraction. Joint extracts are dried over magnesium sulfate. After the solvent has been removed, the residue is vacuum-distilled to collect the fraction with the boiling point of $138-139{ }^{\circ} \mathrm{C} / 5 \mathrm{~mm} \mathrm{Hg}$ and the output of the target product $(34.0 \mathrm{~g}$, colorless oil) of $80 \%$.

Bis-3,3'-bitolyl production from magnesiumorganic derivative, using copper (II) chloride

Grignard reagent is produced using 34.2 $\mathrm{g}(0.200 \mathrm{~mol}) 3$-bromotoluene and $4.9 \mathrm{~g}$ magnesium $(0.200 \mathrm{~mol})$ in $80 \mathrm{ml}$ anhydrous diethyl ether. $30.0 \mathrm{~g}$ ( $0.220 \mathrm{~mol}) \mathrm{CuCl}_{2}$ suspension in $60 \mathrm{ml}$ diethyl ether is added to the solution produced under ice cooling. The mixture is mixed at the boiling point for 12 hours. The reaction mixture is treated with ice and hydrochloric acid, followed by ether layer separation and drying over sodium sulfate. The product is distilled to collect the fraction with the boiling point of $138-139{ }^{\circ} \mathrm{C} / 5 \mathrm{~mm} \mathrm{Hg}$ and the output of $11.3 \mathrm{~g}$ $(62 \%)$ colorless oil.

Bis-3,3'-bitolyl production from magnesiumorganic derivative, using TEMPO

3-Tolylmagnesium bromide solution $(1.54 \mathrm{mmol})$ is added to TEMPO solution $(261 \mathrm{mg}$, $1.66 \mathrm{mmol}, 1.08$ eq.) in anhydrous THF (3 ml) at room temperature. The reaction mixture produced is boiled for $5 \mathrm{~min}$, cooled down to room temperature and poured into the mixture of diethyl ether $(30 \mathrm{ml})$ and concentrated aqueous solution of ammonium chloride $(10 \mathrm{ml})$. Once separated, a water layer is extracted twice with diethyl ether $(30 \mathrm{ml})$, and joint organic phases are flushed with saturated salt solution $(20 \mathrm{ml})$ and dried over magnesium sulfate. The product is separated by means of flash-chromatography $\left(\mathrm{SiO}_{2}\right.$, size: $60-120 \mu \mathrm{m}$, eluent pentane) with the output of $95 \%(136 \mathrm{mg})$.

Bis-3,3'-bitolyl production from magnesiumorganic compound, using anhydrous iron chloride, oxygen and 2,2'-bipyridine

An anhydrous $\mathrm{FeCl}_{3}(0.12 \mathrm{mmol})$ and Bipy (0.24 $\mathrm{mmol})$ are dissolved in 3-ml dry THF inside Schlenk tube, followed by adding 3-tolylmagnesium bromide solution $(2.0 \mathrm{mmol})$ under nitrogen atmosphere. The mixture produced is degassed and filled with pure oxygen from the oxygen cushion, followed by $10 \mathrm{~min}$. mixing of the reaction mixture at room temperature. The end of this reaction is followed by adding $10 \mathrm{ml}$ ethyl acetate and solvent stripping, while the residue is purified by flash-chromatography $\left(\mathrm{SiO}_{2}\right.$, size: $60-120 \mu \mathrm{m}$, eluent pentane) with the output of $76 \%(138 \mathrm{mg})$.

Bis-3,3'-bitolyl production from magnesiumorganic derivative, using Tetrakis (triphenylphosphine) palladium

$\mathrm{Pd}\left[\mathrm{PPh}_{3}\right]_{4}(8.80 \mathrm{~g}, 0.007 \mathrm{~mol})$ is added to 3-bromotoluene solution $(65.5 \mathrm{~g}, 0.383 \mathrm{~mol})$ in tetrahydrofuran $(200 \mathrm{ml})$ under argon atmosphere. Grignard solution, produced from 3-bromotoluene (65.5 g, $0.383 \mathrm{~mol}$ ) and magnesium turnings (9.65 $\mathrm{g}, 0.402 \mathrm{~mol}$ ) in 100-ml THF, is added drop-wise to the initial mixture under its gentle boiling and boiled for 1 hour. After the solvent has been stripped, the residue is treated with the mixture of $200 \mathrm{ml}$ water and $300 \mathrm{ml}$ heptane, followed by acidification with hydrochloric acid to completely dissolve the residue. Once an organic layer has been separated, a water layer is extracted with heptane, followed by residue distillation to collect the fraction at $138-139{ }^{\circ} \mathrm{C} / 5 \mathrm{~mm} \mathrm{Hg}$ and the output of $58.0 \mathrm{~g}(83 \%)$ of colorless oil.

\section{Grignard reagent production from perfluororomobenzene \\ $28.2 \mathrm{ml}(0.222 \mathrm{~mol})$ bromopentafluorobenzene} is added drop-wise to $5.40 \mathrm{~g}(0.222 \mathrm{~mol})$ of magnesium turnings in $150 \mathrm{ml}$ diethyl ether for an hour and at the speed that maintains quiet boiling. The mixture is boiled for another $25 \mathrm{~min}$. till magnesium is completely dissolved.

Decafluorobiphenyl production from magnesiumorganic derivative, using nickel acetylacetonate

A catalyst, nickel acetylacetonate $(1.1 \mathrm{~g}$, $0.0044 \mathrm{~mol}$ ), is added to bromopentafluorobenzene (28.2 $\mathrm{ml}, 0.222 \mathrm{~mol})$ solution in diethyl ether $(140 \mathrm{ml})$ under nitrogen atmosphere. Preliminary produced Grignard reagent solution $(0.222 \mathrm{~mol})$ is added drop-wise to the initial mixture at the speed that maintains moderate boiling. The reaction mixture is boiled for three hours, followed by ether stripping and treating the deposit produced with $200 \mathrm{ml}$ water and $300 \mathrm{ml}$ hexane. To completely dissolve the residue a hydrochloric acid is added, followed by hexane extraction. Joint extracts are dried over magnesium sulfate. After the solvent has 
been removed, the residue is vacuum-distilled to collect the fraction with the boiling point of $94-95{ }^{\circ} \mathrm{C} / 20 \mathrm{~mm} \mathrm{Hg}$, accompanied by simultaneous cooling down of the receiver with ice. The output is $22.4 \mathrm{~g}$ (61\% of estimated value) of white solid substance with the boiling point of 68.5-69.5 ${ }^{\circ} \mathrm{C}$.

\section{RESULTS AND DISCUSSION}

Method selection criteria were the minimum number of stages, availability and cost of initial reagents, process simplicity and method reproducibility and scalability required for developing process procedure.

Ullmann reaction with 3-iodotoluene over activated copper was conducted in two variations: without solvent (Variation A) and in DMF (Variation B).

Product output of the Variation A ranges between 25 and $42 \%$, while that of the Variation reaches 45 to $60 \%$. The drawback of this method is high cost of initial 3-iodotoluene mostly comprising iodine. Low output of the end product makes this method difficult to use for producing 3,3'-bitolyl within the process. That is why the authors drew their attention to the Grignard reaction.

Since the discovery of magnesiumorganic compounds by Grignard at the start of the $20^{\text {th }}$ century till the present time this reaction has been mainly used for producing symmetrical biaryl derivatives. Various catalysts and method modifications allow to produce high outputs of the products of cross-coupling reaction. At the first stage of this reaction 3-chloro- and 3-bromotoluenes reacted easily to magnesium in tetrahydrofuran or diethyl ether. At the second stage Grignard reacted to aryl halides over different catalysts. The results obtained are shown in Table 2.

The most interesting catalysts are iron salts and complexes. However, the authors did not manage to achieve high output of 3,3'-bitolyl. The best result was achieved when using TEMPO, yet the reaction is poorly scalable due to high cost of the latter. The same drawback is also inherent to tetrakistriphenylpalladium.

Table 2: The conditions and results of Grignard reactions of 3-halotoluenes

\begin{tabular}{|c|c|c|c|}
\hline Initial halide & Catalyst & Specified output, \% & Real output, \% \\
\hline 3-Br-Tol & $\mathrm{Fe}(\mathrm{acac})_{3}$ & $90^{13}$ & 12 \\
\hline 3-Br-Tol & $\mathrm{Fe}(\mathrm{OTf})_{3}$ & $88^{14}$ & 10 \\
\hline 3-Br-Tol & $\mathrm{CuCl}_{2}$ & $64^{15}$ & 62 \\
\hline 3-Br-Tol & $\mathrm{CoCl}_{2}$ & -16 & 48 \\
\hline 3-Br-Tol & $\mathrm{FeCl}_{3}, \mathrm{O}_{2}$, bipy & $80^{17}$ & 76 \\
\hline 3-Br-Tol & TEMPO & $98^{18}$ & 95 \\
\hline 3-Br-Tol & $\mathrm{ZnBr}_{2}$ & $92^{13}$ & 25 \\
\hline 3-BrMgTol/3-Br-Tol & $\mathrm{Pd}\left[\mathrm{Ph}_{3}\right]_{4}$ & -19 & $82-84$ \\
\hline 3-CIMgTol/3-Br-Tol & $\mathrm{Pd}\left[\mathrm{Ph}_{3}\right]_{4}$ & -18 & $78-80$ \\
\hline 3-BrMgTol/3-Br-Tol & $\mathrm{Ni}(\text { acac })_{2}$ & -20 & 80 \\
\hline 3-CIMgTol/3-Br-Tol & $\mathrm{Ni}(\text { acac })_{2}$ & -19 & 75 \\
\hline
\end{tabular}

The optimal method of producing 3,3 '-bitolyl is cross-coupling reaction between 3-tolylmagnesium halide and 3-bromotoluene over nickel salts, since using copper (II) chloride resulted in slightly lower output.

The logical extension of haloarene cross-coupling reaction studies was investigating the conditions of producing decafluorodiphenyl within the framework of the FTP «Development of simple and environmentally safe technology for producing polymer materials that are flexible over wide temperature range and designed for photosensitive elements» (Code 2016-14-579-009-323). Decafluorodiphenyl is used as initial reagent for producing octafluorobenzidine ${ }^{21}$, a monomer used for polymer synthesis ${ }^{22}$, particularly fluorinated polyimide ${ }^{23}$ films. Aromatic polyimides have been 
paid great attention in the microelectronics as interlayer dielectrics due to their properties, including high thermal stability, chemical resistance and good mechanical and electrical properties. In particular, polyimides, which are stable at high temperature, are producing by condensing diamine and pyromellitic ${ }^{24}$ anhydrite.

Decafluorodiphenyl is produced using Ullmann reaction with chloropentafluorobenzene ${ }^{25-26}$ over copper, while slightly raising temperature from 230 to $320-360{ }^{\circ} \mathrm{C}$ increases reaction output a little (from $69 \%$ to $73 \%$ ). Using bromopentafluorobenzene under the same conditions substantially increase product output ${ }^{27-29}$ (from $87 \%$ to $91 \%$ ), yet replacing copper with activated nicke ${ }^{30}$, produced by reducing nickel bromide or nickel iodide with lithium naphthalede, is unsuccessful $(37-49 \%)$.

Noteworthy, incase of iodopentafluorobenzene the last approach leads to quantitative course (according to GC data) of the reaction 29,31 . This method is difficult to be scaled due to high cost of nickel iodide and aryl iodide and the use of fire-hazardous lithium and dimethoxyethane. Replacing nickel iodide with more available copper (I) chloride leads to slight decrease in the output ${ }^{32}$ $(91 \%)$ with the same preparatory drawbacks.

More convenient method is heating iodopentafluorobenzene over copper in the autoclave ${ }^{27,33}$ with the output of $72-87 \%$.

The highest output $(96 \%)$ of the product was achieved by boiling bromopentafluorobenzene ${ }^{34}$ in DMF over activated copper. Noteworthy, the other authors $^{35}$ achieved an output not exceeding $71 \%$ under similar conditions (7-hour boiling).

As for Grignard reagents, pentafluorophenyl magnesium chloride ${ }^{36}$ is turned into decafluorodiphenyl, with its output of $72-84 \%$, over copper (I) iodide, accompanied by producing pentafluorophenyl magnesium iodide $(8-11 \%)$ as a by-product. In case of pentafluorophenyl magnesium bromide and $\mathrm{CoCl}_{2}$, the reaction results in unsatisfactory ${ }^{26-27}$ output, while using $\mathrm{CuBr}$ leads to production of tetramer ${ }^{37-38}$ ( $70 \%$ output), which forms perfluorobiphenyl (68\% output) when being boiled with copper (II) bromide in hexane.
Pentafluorophenyl bromide is known to be used in the Heck reaction with pentafluorobenzene over dicyclohexyl(2',6'-dimethoxybiphenyl-2-yl) phosphine ${ }^{39}$ and palladium acetate (83\% output). When bromopentafluorobenzene reacts to $\mathrm{CuCN}^{40}$, 1-bromo-2,3,4,5-tetrafluorobenzene ${ }^{41}$ and 1-chloro1,2-difluoroethylene ${ }^{42}$, the target product forms as a by-product ( $9-18 \%$ output).

Another interesting approach is using pentafluorophenyl iodide in the reaction with potassium perfluorobenzoate ${ }^{43}$ over copper (I) iodide ( $80 \%$ output).

Recently ${ }^{44}$ pentafluorobenzene dimerization reaction was conducted over palladium acetate and silver carbonate ( $60 \%$ output).

In 2014 a cross-coupling reaction between perfluorophenylboronic ${ }^{45}$ acid and gold complex [Au'"' $\left.\left(\mathrm{C}_{6} \mathrm{~F}_{5}\right)\left(\mathrm{PPh}_{3}\right) \mathrm{Cl}_{2}\right]$ (89\% output) was published.

As in 3.3'-bitolyl case, the methods of using activated metals and pentafluorophenyl bromide, which is more available comparing to iodo derivatives, turned out to be the most preparatory ones.

Using activated copper under DMF led to the target product's output of $92 \%$. Similarly to 3-tolyl bromide case, the authors produced Grignard reagent, which reacts to the relevant aryl bromide over nickel acetylacetonate and is featured by lower output $(61 \%)$.

\section{CONCLUSION}

As result of investigating various methods of 3-tolylhalides and pentafluorophenyl bromide cross-coupling, it was found that the optimal method was using Grignard reagent over nickel acetylacetonate or activated copper over DMF respectively.

\section{ACKNOWLEDGMENT}

Applied researches are carried out with state financial support represented by the Ministry of Education of Russia under the Agreement on granting subsidies No. 14.625.21.0037 of October 03, 2016. Unique identifier for Applied Scientific Researches (project) RFMEFI62516X0037. 


\section{REFERENCES}

1. Nagai, T.; Arikawa, Y.; Hosoda, H.; loka, Y.; Hasegawa, A.;Wada, K.; Takaoku, S.;Takata, M.; Noritake, K.; Minami, Y.; Watanabe, K.; Yamanoi, K.; Nakamura, H.; Watari, T.; Cadatal-Raduban, M.; Shimizu, T.; Sarukura, N.; Nakai, M.; Norimatsu, T.; Azechi, H. EPJ Web of Conferences. 2013, 59, 13012 (doi: 10.1051/epjconf/2013513012).

2. Berlman I. B.; Lutz S. S.; Flournoy J. M.; Ashford C. B.; Franks L. A.; Lyons P. B. Nucl. Instrum. Methods Phys. Res. 1984, 225, 78-82.

3. Ma, N.; Zhu, Z.; Wu, Y. Tetrahedron. 2007, 63(22), 4625-4629.

4. $\quad$ Wang, L; Lu, W. Org. Lett. 2009, 11(5), 1079-1082.

5. Venkatraman, S.; Li, C.-J. Tetr. Lett. 2000, 41(25), 4831-4834.

6. Venkatraman, S.; Huang, T.; Li, C.-J. Adv. Synth. Catal. 2002, 344, 399-405.

7. Schultz, G.; Rohde, G.; Vicari, F. Ber. Dtsch. Chem. Ges. 1904, 37(2), 1401-1402.

8. Schultz, G.; Rohde, G.; Vicari, F. Liebigs Ann. Chem. 1907, 352(1),_111-131.

9. Ullmann, F.; Meyer, G. Liebigs Ann. Chem. 1904, 332(1-2), 38-81.

10. Takahara, S.; Urano, T.; Kitamura, A.; Sakuragi, H.; Kikuchi, O.; Yoshida, M.; Tokumaru, K. Bull. Chem. Soc. Jpn, 1985, 58(2), 688-697.

11. Kornblum, N.; Kendall, D. L. J. Am. Chem. Soc. 1952, 74(22), 5782-5782.

12. Eisch, J. J.; Hallenbeck, L. E.; Han, K. I. J. Am. Chem. Soc. 1986, 108, 7763-7767.

13. Xu, X.; Cheng, D.; Pei, W. J. Org. Chem. 2006, 71(17), 6637-6639.

14. Castro, C. E.; Andrew, J.; Keefer, R. M. J. Am. Chem. Soc. 1958, 80, 2322-2326

15. Bock, L. H.; Moyer, W. W.; Adams, R. J. Am. Chem. Soc. 1930, 52(5), 2054-2056.

16. Kharasch, M. S., Fields, E. K., J. Am. Chem. Soc. 1941, 63(9), 2316-2320.

17. Liu, W.; Lei, A. Tetr. Lett. 2008, 49(4), 610-613.

18. Maji, M. S.; Studer, A. Synthesis, 2009, 14, 2467-2470.

19. Cepanec, I., Synthesis of Biaryls, 1th Ed., Netherlands, Elsevier, 2004, 86-94.

20. Ikoma, Y.; Taya, F.; Ozaki, E.-i.; Higuchi, S.; Naoi, Y.; Fuji-i, K. Synthesis .1990, 2, 147-148.

21. Furin, G. G.; Grebenshchikova, G. F.; Lvova, A. Y.; Vlasov, V. M.; Yakobson, G. G. Chapter 3. Fluoroaromatic Compounds (in Syntheses of Fluoroorganic Compounds, ed. Knunyants I. L.; Yakobson G. G.), Berlin, Heidelberg Springer-Verlag, 1985, 109-232.
22. Tkachenko, I. M.; Belov, N. A.; Kobzar, Y. L.; Dorokhin, A. V.; Shekera, O. V.; Shantarovich, V. P.; Bekeshev, V. G.; Shevchenko, V. V. J. Fluor. Chem. 2017, 195, 1-12.

23. Yeo, H.; Goh, M.; Ku, B.-C.; You, N.-H., Polymer (United Kingdom), 2015, 76, 280-286.

24. Wozniak, A. I.; Ivanov, V.S.; Kosova, O.V.;Yegorov, A. S. Orient. J. Chem. 2016, 32(6), 2967-2974.

25. Brooke, G.; Chambers, R.; Heyes, J.; Musgrave, W. K. R. J. Chem. Soc. 1964, 729-733.

26. Yakobson, G. G.; Shteingarts, V. D.; Miroshnikov, A. I.; Vorozhtsov, N. N. Dokl. Acad. Nauk. SSSR, 1964, 159, 1347.

27. Pummer, W. J.; Wall, L. A. J. Res. Nat. Bur. Stand. A. Phys. Ch. 1959, 63, 167.

28. Pummer, W. J.; Wall, L. A. Preparation of pentafluoroiodobenzene. Patent US 3046313 A. 1962.

29. Nield, E.; Stephens, R.; Tatlow, J. C. J. Chem. Soc. 1959, 166-171.

30. Matsumoto, H.; Inaba, S.-i.; Rieke, R. D. J. Org. Chem. 1983, 48, 840-843.

31. Inaba, S.-i.; Matsumoto, H.; Rieke, R. D. Tetr. Lett. 1982, 23(41), 4215-4216.

32. Ebert, G. W.; Rieke, R. D. J. Org. Chem. 1984, 49, 5280-5282.

33. Birchall, J. M.; Hazard, R.; Haszeldine, R. N.; Wakalski, W. W. J. Chem. Soc. (C). 1967, 47-50.

34. Thrower, J.;White, M. A. Polym. Prepr. Am. Chem. Soc. Div. Polym. Chem. 1966, 7, 1077-1083.

35. Chambers, R. D.; Spring, D. J. J. Chem. Soc. (C), 1968, 2394-2397.

36. Rahman, M. T.; Gilman, H. J. Ind. Chem. Soc. 1974, 51, 1018-1023.

37. Cairncross, A.; Sheppard, W. A. J.Am. Chem. Soc. 1968, 90, 2186-2187.

38. Cairncross, A.; Sheppard, W. A.; Wonchoba, E. Org. Synth. 1979, 59, 122-131.

39. Lafrance, M.; Shore, D.; Fagnou, K. Org. Lett. 2006, 8(22), 5097-5100.

40. Belf, L.; Buxton, M.; Fuller, G. J. Chem. Soc. 1965, 3372-3379.

41. Callander, D. D.; Coe, P. L.; Tatlow, J. C. Tetrahedron 1966, 22(2), 419-432.

42. Camaggi, G.; Campbell, S. F.; Perry, D. R. A.; Stephens, R.; Tatlow, J. C. Tetrahedron. 1965, 22(6), 1755-1763.

43. Shang, R.;Fu, Y.;Wang, Y.; Xu, Q.;Yu, H.-Z.; Liu, L. Angew. Chem. Int. Ed. 2009, 48(49), 9350-9354.

44. Chen, F.; Feng, Z;; He, C.-Y.; Wang, H.-Y.; Guo, Y.-L.; Zhang, X. Org. Lett. 2012, 14(4), 1176-1179.

45. Hofer, M.; Gomez-Bengoa, E.; Nevado, C. Organometallics. 2014, 33(6), 1328-1332. 